\title{
Synthesis and Characterization of $\alpha$-Titanium Phosphate/Propylamine Intercalation Compounds Containing Transition-Metal Ions
}

\author{
Belén F. Alfonso ${ }^{a}, *$, Camino Trobajo ${ }^{b}$, Miguel A. Salvadóc, Pilar Pertierrac ${ }^{c}$, Santiago García-Granda ${ }^{\mathrm{c}}$, Jesús \\ Rodríguez-Fernández ${ }^{\mathrm{d}}$, Jesús A. Blanco ${ }^{\mathrm{a}}$, and José R. García ${ }^{\mathrm{b}}$
}

\author{
Oviedo/Spain, a Departamento de Física, ${ }^{\mathrm{b}}$ Departamento de Química Orgánica e Inorgánica y ${ }^{\mathrm{c}}$ Departamento Química Física y \\ Analítica, Universidad de Oviedo \\ d Santander, CITIMAC, Facultad de Ciencias, Universidad de Cantabria
}

Received November 30th, 2004; accepted March 15th, 2005.

\begin{abstract}
Polycrystalline intercalated $\operatorname{TiM}_{\mathrm{x}} \mathrm{H}_{2-\mathrm{nx}}\left(\mathrm{PO}_{4}\right)_{2}$. $\mathrm{yC}_{3} \mathrm{H}_{7} \mathrm{NH}_{2} \cdot \mathrm{wH}_{2} \mathrm{O}$ compounds with transition metal (TM) ions $\left(\mathrm{M}^{\mathrm{n}+}=\mathrm{Co}^{2+}, \mathrm{Ni}^{2+}, \mathrm{Fe}^{3+}\right.$ or $\left.\mathrm{Cr}^{3+}\right)$ have been prepared by means of an indirect route and characterised using X-ray diffraction, scanning electron microscopy, chemical and thermal analysis, X-ray absorption and magnetic measurements. These novel pillared layered materials, which were obtained from the monoclinic $\left(P 2_{1} / \mathrm{c}\right.$ space group) $\alpha$ - $\mathrm{Ti}\left(\mathrm{HPO}_{4}\right)_{2} \cdot \mathrm{H}_{2} \mathrm{O}$ phase, lose its crystallinity after intercalation. However all the TM ions are octahedrally surrounded by 6
\end{abstract}

oxygen atoms, although the $\mathrm{X}$-ray absorption spectra evidence a clear dependence on the temperature. Surprisingly, all the materials behave as paramagnetic down to $1.5 \mathrm{~K}$, but they exhibit different colours, what means that they are optically active $\left(\mathrm{Co}^{2+}\right.$ : violet; $\mathrm{Ni}^{2+}$ : pale green; $\mathrm{Fe}^{3+}$ : yellow; $\mathrm{Cr}^{3+}$ : dark green).

Keywords: $\alpha$-Titanium phosphate; Layered compounds; Intercalation; Ion exchange; Transition metals; Magnetic properties

\section{Introduction}

Over the last decade, the field of functional molecular materials has experimented a large progress since the discovery of a great variety of emergent solid state properties, such as conductivity, superconductivity, non linear optics, and magnetic order [1]. Crystal engineering, through different synthesis routes, is searching for new physical-chemical phenomena and potent novel applications where two of the above mentionated properties could be combined. In particular, the magnetic behaviour depends strictly on the crystal building in which $3 \mathrm{~d}$ cations are located. Likewise, ligand type, nature of binding ions, total charge, polarity of peripheral groups are important factors in the network construction. The search for new synthetic routes for achieving new materials is of current interest in modern inorganic chemistry [2].

In the last time many compounds have been synthesized in which magnetic interactions between transition metal ions are essentially confined to one or two dimensions [3]. For example the layer perovskites $\mathrm{M}_{2}^{\mathrm{I}} \mathrm{M}^{\mathrm{II}} \mathrm{X}_{4}$, which adopt structures based on the $\mathrm{K}_{2} \mathrm{NiF}_{4}$ type lattice, have proved a rich source for the magnetic system model [4]. All compounds of this series have relatively high symmetry, and the exchange interaction, responsible for establishing of the

\footnotetext{
* Belén F. Alfonso

Departamento de Física

Edificio Departamental Zona Este. E.P.S.I.G. Campus de Viesques

Universidad de Oviedo

E-33204 Gijón/Spain

Fax: +34-985182390

E-mail address: mbafernandez@uniovi.es
}

magnetic order, is mediated by monoatomic anions. Other compounds based on hybrid organic/inorganic crystals have been studied in which the exchange is provided by complex ions [5]. In this context, the layered metal phosphates have been poorly explored [6] until now.

As a part of an ongoing research program undertaken by our group to synthesize novel layered materials, different $3 \mathrm{~d}$ cations $\left(\mathrm{Co}^{2+}, \mathrm{Ni}^{2+}, \mathrm{Fe}^{3+}\right.$ or $\left.\mathrm{Cr}^{3+}\right)$ were inserted between the layers of metal phosphates.

The first crystalline metal(IV) phosphate, $\mathrm{Zr}\left(\mathrm{HPO}_{4}\right)_{2} \cdot \mathrm{H}_{2} \mathrm{O}$, was obtained by reflux in $\mathrm{H}_{3} \mathrm{PO}_{4}$ of a zirconium phosphate gel [7]. This crystalline layered phase [8] can also be synthesized by hydrothermal methods [9] and by direct precipitation with [10] or without [11] prior formation of zirconium(IV) fluorocomplexes. Later, independent works of several laboratories [12] succeed in synthesizing an interesting family of these materials: $\mathrm{M}\left(\mathrm{HPO}_{4}\right)_{2} \cdot \mathrm{H}_{2} \mathrm{O}(\mathrm{M}=$ $\mathrm{Ti}, \mathrm{Zr}, \mathrm{Hf}, \mathrm{Sn}, \mathrm{Pb}$ ).

The $\alpha$-titanium phosphate, $\alpha$-Ti $\left(\mathrm{HPO}_{4}\right)_{2} \cdot \mathrm{H}_{2} \mathrm{O}$, is a layer compound with a flexible layer structure that, although it has ion-exchange properties, presents low affinity towards transition-metal ions. The synthesis of ion-exchange phases with elements of the first short period is possible by means of an indirect route [13]. In a first stage, by reaction between the acid inorganic solid ( $\alpha$-titanium phosphate) and the vapour of an organic base (e.g., $n$-alkylamine), an intercalation compound (in this case, $\left.\mathrm{Ti}\left(\mathrm{HPO}_{4}\right)_{2} \cdot 2 \mathrm{C}_{\mathrm{n}} \mathrm{H}_{2 \mathrm{n}+1} \mathrm{NH}_{2} \cdot \mathrm{H}_{2} \mathrm{O}\right)$ is obtained. In a second step, the intercalation compound reacts with an aqueous solution of the desired metal salt, and the substitution of interlayer organic cation by the inorganic metal cation takes place [14]. 
In this paper, the synthesis and characterization of both $\mathrm{TiM}_{\mathrm{x}}^{\mathrm{II}} \mathrm{H}_{2-2 \mathrm{x}}\left(\mathrm{PO}_{4}\right)_{2} \cdot \mathrm{yC}_{3} \mathrm{H}_{7} \mathrm{NH}_{2} \cdot \mathrm{wH}_{2} \mathrm{O}\left(\mathrm{M}^{\mathrm{II}}=\mathrm{Co}, \mathrm{Ni}\right)$ and $\mathrm{TiM}^{\mathrm{III}}{ }_{\mathrm{x}} \mathrm{H}_{2-3 \mathrm{x}}\left(\mathrm{PO}_{4}\right)_{2} \cdot \mathrm{yC}_{3} \mathrm{H}_{7} \mathrm{NH}_{2} \cdot \mathrm{wH}_{2} \mathrm{O}\left(\mathrm{M}^{\mathrm{III}}=\mathrm{Fe}, \mathrm{Cr}\right) \mathrm{ma}-$ terials is reported.

\section{Experimental Section}

\subsection{Synthesis}

The $\alpha-\mathrm{Ti}\left(\mathrm{HPO}_{4}\right)_{2} \cdot \mathrm{H}_{2} \mathrm{O}(\alpha-\mathrm{TiP})$ was obtained following the Alberti method [15] using $10 \mathrm{M} \mathrm{H}_{3} \mathrm{PO}_{4}$ and reflux times of 48 hours. The starting titanium phosphate gel was prepared by precipitation of a $\mathrm{TiCl}_{4} / \mathrm{HCl}$ aqueous solution with dilute $\mathrm{H}_{3} \mathrm{PO}_{4}$ [16]. The crystalline solid was washed with distilled water until $\mathrm{pH}=3.5$. Intercalation compounds with $n$-propylamine, represented by Eq. (1), were obtained by placing for six days the $\alpha$-TiP in an atmosphere saturated with $n$-propylamine vapour at room temperature [17]. The samples were dried in air at $50^{\circ} \mathrm{C}$. The intercalation process leads to the formation of a compound $(\alpha-\operatorname{TiP} / \operatorname{Pr} A)$ in which the amine reaches the all active centers of the material. The basal spacing of this material is $16.9 \AA(7.6 \AA$ for $\alpha$-TiP), with a ion-exchange theoretical capacity of $5.32 \mathrm{meq} / \mathrm{g}(7.75 \mathrm{meq} / \mathrm{g}$ for $\alpha-\mathrm{TiP})$.

$$
\alpha-\mathrm{Ti}\left(\mathrm{HPO}_{4}\right)_{2} \cdot \mathrm{H}_{2} \mathrm{O}+2 \mathrm{C}_{3} \mathrm{H}_{7} \mathrm{NH}_{2} \rightarrow \mathrm{Ti}\left(\mathrm{HPO}_{4}\right)_{2} \cdot 2 \mathrm{C}_{3} \mathrm{H}_{7} \mathrm{NH}_{2} \cdot \mathrm{H}_{2} \mathrm{O}
$$

The $\alpha-\operatorname{TiP} / \operatorname{PrA}$ material, obtained previously, was equilibrated with $\mathrm{MCl}_{\mathrm{n}}$ aqueous solutions [ $\mathrm{n}$-valent metal cation $=$ cobalt(II), nicke1(II), iron(III), chromium(III)] containing different amounts of the transition-metal $\left(\mathrm{N}=1,2,3,4,5,6,8,10\right.$ meq $\mathrm{M}^{\mathrm{n}+}$ per gram of solid). The mixture stayed in a bath at $25.0 \pm 0.1^{\circ} \mathrm{C}$ with continuous agitation during 48 hours. The solids, $\mathrm{TiM}_{\mathrm{x}} \mathrm{H}_{2-\mathrm{nx}}\left(\mathrm{PO}_{4}\right)_{2} \cdot \mathrm{y}$ $\mathrm{C}_{3} \mathrm{H}_{7} \mathrm{NH}_{2} \cdot \mathrm{wH}_{2} \mathrm{O}\left(\mathrm{M}_{\mathrm{N}} \mathrm{TiP}\right)$, were separated of the liquid fractions by centrifugation, washed with distilled water, and dried in air at room temperature.

Table 1 Values of $\mathrm{x}, \mathrm{y}$, and $\mathrm{w}$ in the compounds: $\mathrm{TiM}_{\mathrm{x}}^{\mathrm{II}} \mathrm{H}_{2-2 \mathrm{x}}\left(\mathrm{PO}_{4}\right)_{2} \cdot \mathrm{yC}_{3} \mathrm{H}_{7} \mathrm{NH}_{2} \cdot \mathrm{wH}_{2} \mathrm{O}\left(\mathrm{M}^{\mathrm{II}}=\mathrm{Co}, \mathrm{Ni}\right)$.

\begin{tabular}{llllllll}
\hline Sample & $x$ & $y$ & $w$ & Sample & $x$ & $y$ & $w$ \\
\hline $\mathrm{Co}_{1} \mathrm{TiP}$ & 0.29 & 0.84 & 3.0 & $\mathrm{Ni}_{1} \mathrm{TiP}$ & 0.26 & 0.83 & 3.6 \\
$\mathrm{Co}_{2} \mathrm{TiP}$ & 0.51 & 0.61 & 4.3 & $\mathrm{Ni}_{2} \mathrm{TiP}$ & 0.49 & 0.65 & 5.1 \\
$\mathrm{Co}_{3} \mathrm{TiP}$ & 0.86 & 0.58 & 5.1 & $\mathrm{Ni}_{3} \mathrm{TiP}$ & 0.78 & 0.41 & 7.1 \\
$\mathrm{Co}_{4} \mathrm{TiP}$ & 0.90 & 0.35 & 5.7 & $\mathrm{Ni}_{4} \mathrm{TiP}$ & 0.98 & 0.23 & 6.7 \\
$\mathrm{Co}_{5} \mathrm{TiP}$ & 0.98 & 0.09 & 6.6 & $\mathrm{Ni}_{5} \mathrm{TiP}$ & 0.98 & 0.05 & 6.8 \\
$\mathrm{Co}_{6} \mathrm{TiP}$ & 1.00 & 0.11 & 6.3 & $\mathrm{Ni}_{6} \mathrm{TiP}$ & 0.97 & 0.07 & 6.7 \\
$\mathrm{Co}_{8} \mathrm{TiP}$ & 0.98 & 0.07 & 6.4 & $\mathrm{Ni}_{8} \mathrm{TiP}$ & 0.97 & 0.05 & 7.2 \\
$\mathrm{Co}_{10} \mathrm{TiP}$ & 0.98 & 0.09 & 6.5 & $\mathrm{Ni}_{10} \mathrm{TiP}$ & 0.98 & 0.07 & 7.2 \\
\hline
\end{tabular}

Table 2 Values of $\mathrm{x}, \mathrm{y}$, and $\mathrm{w}$ in the compounds: $\mathrm{TiM}_{\mathrm{x}}^{\mathrm{III}} \mathrm{H}_{2-3 \mathrm{x}}\left(\mathrm{PO}_{4}\right)_{2} \cdot \mathrm{yC}_{3} \mathrm{H}_{7} \mathrm{NH}_{2} \cdot \mathrm{wH}_{2} \mathrm{O}\left(\mathrm{M}^{\mathrm{III}}=\mathrm{Fe}, \mathrm{Cr}\right)$.

\begin{tabular}{llllllll}
\hline Sample & $x$ & $y$ & $w$ & Sample & $x$ & $y$ & w \\
\hline $\mathrm{Fe}_{1} \mathrm{TiP}$ & 0.11 & 1.11 & 3.3 & $\mathrm{Cr}_{1} \mathrm{TiP}$ & 0.12 & 1.06 & 3.8 \\
$\mathrm{Fe}_{2} \mathrm{TiP}$ & 0.19 & 1.02 & 3.7 & $\mathrm{Cr}_{2} \mathrm{TiP}$ & 0.22 & 0.96 & 5.0 \\
$\mathrm{Fe}_{3} \mathrm{TiP}$ & 0.31 & 0.81 & 4.7 & $\mathrm{Cr}_{3} \mathrm{TiP}$ & 0.34 & 0.78 & 7.5 \\
$\mathrm{Fe}_{4} \mathrm{TiP}$ & 0.33 & 0.52 & 5.5 & $\mathrm{Cr}_{4} \mathrm{TiP}$ & 0.43 & 0.49 & 8.9 \\
$\mathrm{Fe}_{5} \mathrm{TiP}$ & 0.47 & 0.17 & 7.8 & $\mathrm{Cr}_{5} \mathrm{TiP}$ & 0.51 & 0.19 & 13.2 \\
$\mathrm{Fe}_{6} \mathrm{TiP}$ & 0.49 & 0.12 & 7.2 & $\mathrm{Cr}_{6} \mathrm{TiP}$ & 0.55 & 0.16 & 12.2 \\
$\mathrm{Fe}_{8} \mathrm{TiP}$ & 0.61 & 0.06 & 7.4 & $\mathrm{Cr}_{8} \mathrm{TiP}$ & 0.57 & 0.12 & 13.1 \\
$\mathrm{Fe}_{10} \mathrm{TiP}$ & 0.63 & 0.01 & 7.7 & $\mathrm{Cr}_{10} \mathrm{TiP}$ & 0.58 & 0.10 & 11.2 \\
\hline
\end{tabular}

The formula data of the synthesized pillared materials, $\mathrm{M}_{\mathrm{N}} \mathrm{TiP}$, are presented in Table 1 for the di-valent transition metal ions and Table 2 for tri-valent transition metal ions.

\subsection{Analytical procedures}

The phosphorus and titanium content in the solids was determined by using a SpectraSpec DCP-AES spectrometer after dissolving a weighed amount in HF aqueous solution. The content in carbon and nitrogen in the solids were made with a micro-analizer Perkin Elmer 2400B. The thermal analysis of solids was performed on a Mettler model TA4000-TG50 (rate of heating $10^{\circ} \mathrm{C} \mathrm{min}^{-1}$, nitrogen atmosphere with a flux volume of $5 \mathrm{ml} \mathrm{min}^{-1}$ ). The $\mathrm{pH}$ of the solutions after the equilibration with the exchanger was measured using a Corning $340 \mathrm{pH}$ meter. Initial and final concentrations of transition-ions in solution were measured using a Perkin Elmer lambda-20 spectrometer. The same equipment allowed the determination of the released phosphate groups, as a phosphorovanadiummolybdate heteropolycomplex [18]. The affinity of the material for the transition-ions was expressed through the conversion values, which were obtained according to the formula in Eq. (2).

$C(\%)=\frac{\text { meq }\left(\mathrm{M}^{\mathrm{n}+}\right) / \mathrm{g}(\alpha-\operatorname{TiP} / \operatorname{Pr} \mathrm{A})}{5.32 \mathrm{meq}\left(\mathrm{H}^{+}\right) / \mathrm{g}(\alpha-\operatorname{TiP} / \operatorname{Pr} \mathrm{A})} \cdot 100$

The powder X-ray diffraction pattern of the solids was performed using a Philips model PW 1729/1720 with $\mathrm{CuK} \alpha$ radiation. The FT-IR data were obtained on a spectrophotometer Perkin Elmer 577, using the $\mathrm{KBr}$ pellet technique. The scanning electronic microscopy (SEM) images were obtained on a JEOL 6100, operating to $20 \mathrm{kV}$.

The X-ray absorption coefficients encompassing the $\mathrm{Co}, \mathrm{Ni}, \mathrm{Fe}$ and $\mathrm{Cr}$ absorption edges were collected using the BM29 beamline at the ESRF (Grenoble, France). It was not very difficult to grind the

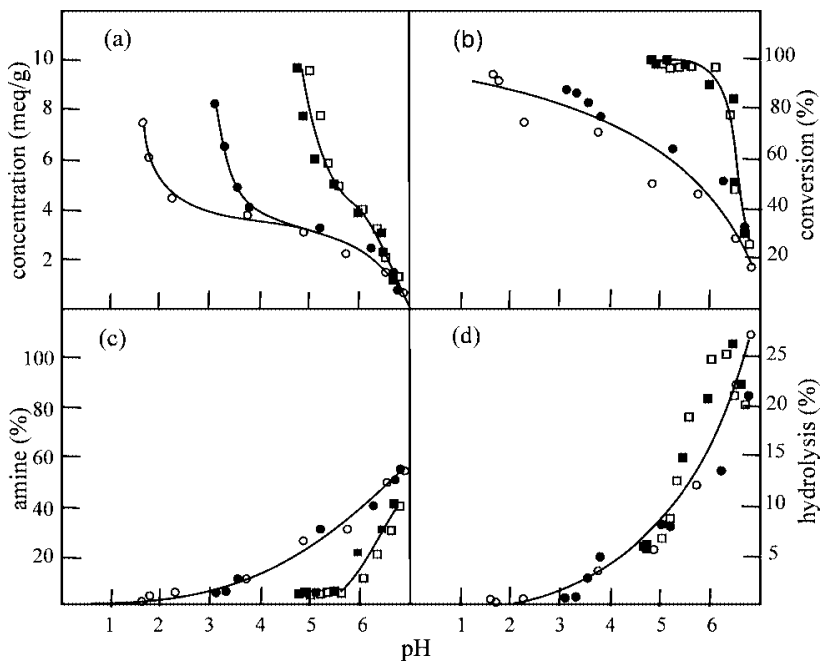

Figure 1 Synthesis data of the materials obtained by treatment of $\alpha$-TiP/PrA $(1 \mathrm{~g})$ with aqueous solutions $(100 \mathrm{ml})$ of metal chloride ( $\mathrm{Co}^{2+}, \square \mathrm{Ni}^{2+}, \bigcirc \mathrm{Fe}^{3+},-\mathrm{Cr}^{3+}$ ) based on $\mathrm{pH}$ of equilibrium solutions: (a) metal cation concentration in the solutions before the reaction, (b) amount of metallic cation retained in solid phase, (c) amount of residual propylamine in solid phase, and (d) degradation of the material. 


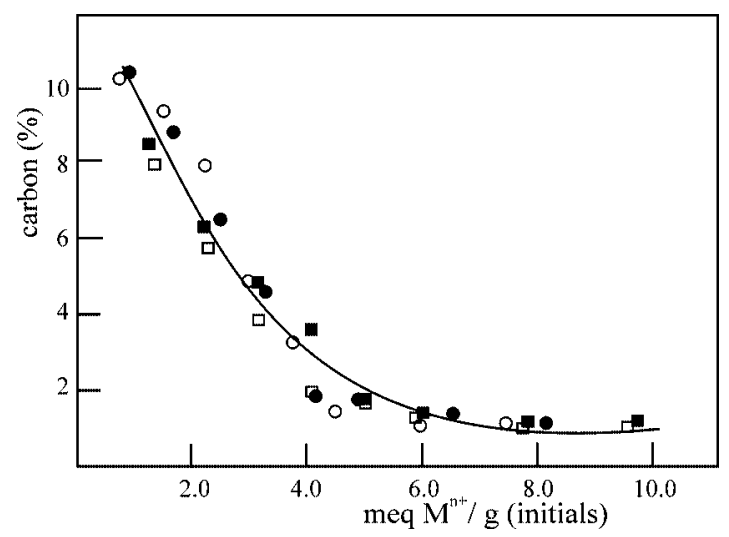

Figure 2 Percentage of carbon content in solid phase $\left(\mathrm{M}_{\mathrm{N}} \mathrm{TiP}\right)$ as a function of the metal cation initial concentration $\left(\square \mathrm{Co}^{2+}, \square\right.$ $\left.\mathrm{Ni}^{2+}, \bigcirc \mathrm{Fe}^{3+}, \bigcirc \mathrm{Cr}^{3+}\right)$ in solution.

powders to a suitable particle size in order to use the Extended Xray absorption fine-structure (EXAFS) transmission mode. EXAFS data were collected from the milled powders and thin foils of $\mathrm{Co}, \mathrm{Ni}, \mathrm{Fe}$ and $\mathrm{Cr}$. Following established EXAFS analysis procedures, a line was fit to the preabsorption edge region and the area under this line and its extrapolation were removed from the spectrum using the VIPER software [19].

Magnetic susceptibility measurements (dc) were performed under an applied magnetic field of $2 \mathrm{kOe}$ over the temperature range 1.8 $\leq \mathrm{T}(\mathrm{K}) \leq 300 \mathrm{~K}$ using a Quantum Design PPMS of the Laboratorio de Física de la Materia Condensada (Universidad de Cantabria, Spain).

\section{Results and Discussion}

In all cases, the contact of the solid with $\mathrm{MCl}_{\mathrm{n}}\left(\mathrm{M}^{\mathrm{n}+}=\right.$ $\left.\mathrm{Co}^{2+}, \mathrm{Ni}^{2+}, \mathrm{Fe}^{3+}, \mathrm{Cr}^{3+}\right)$ aqueous solutions produces materials in which the transition-metal content in solid phase increases as it undergoes his initial concentration in liquid phase, while that both the solution equilibrium $\mathrm{pH}$ and the solid phase propylamine concentration decreases (Figs. 1a, $1 \mathrm{~b}$, and $1 \mathrm{c})$. The $\alpha-\operatorname{TiP} / \operatorname{PrA}$ has higher affinity towards the di-valent cations than towards the tri-valents, and cobaltand nickel-phases easily reach values near to the ion-exchange theoretical capacity. The degradation of the material (Fig. 1d) is independent to the metal-ion type, and it is a function of the equilibrium $\mathrm{pH}$, being practically negligible in the conditions of synthesis appropriate for the transitionmetal phases of greater conversion.

The elementary analysis of solids indicates that the amount of amine in the material decreases with the increase in the amount of retained metal-ion (Fig. 2). The process is visualized by IR (as an example, Figure 3 shows the IR spectra of some iron phases), where the disappearance of the propylamine characteristic bands (between $1629 \mathrm{~cm}^{-1}$ and $1396 \mathrm{~cm}^{-1}$ ) can be observed. The quantification of propylamine concentration in solid phase, and its comparison with the transition-metal concentration (Fig. 4) indicates that, in strict sense, the reaction cannot be considered like a process of ion-exchange between both propylamonium and

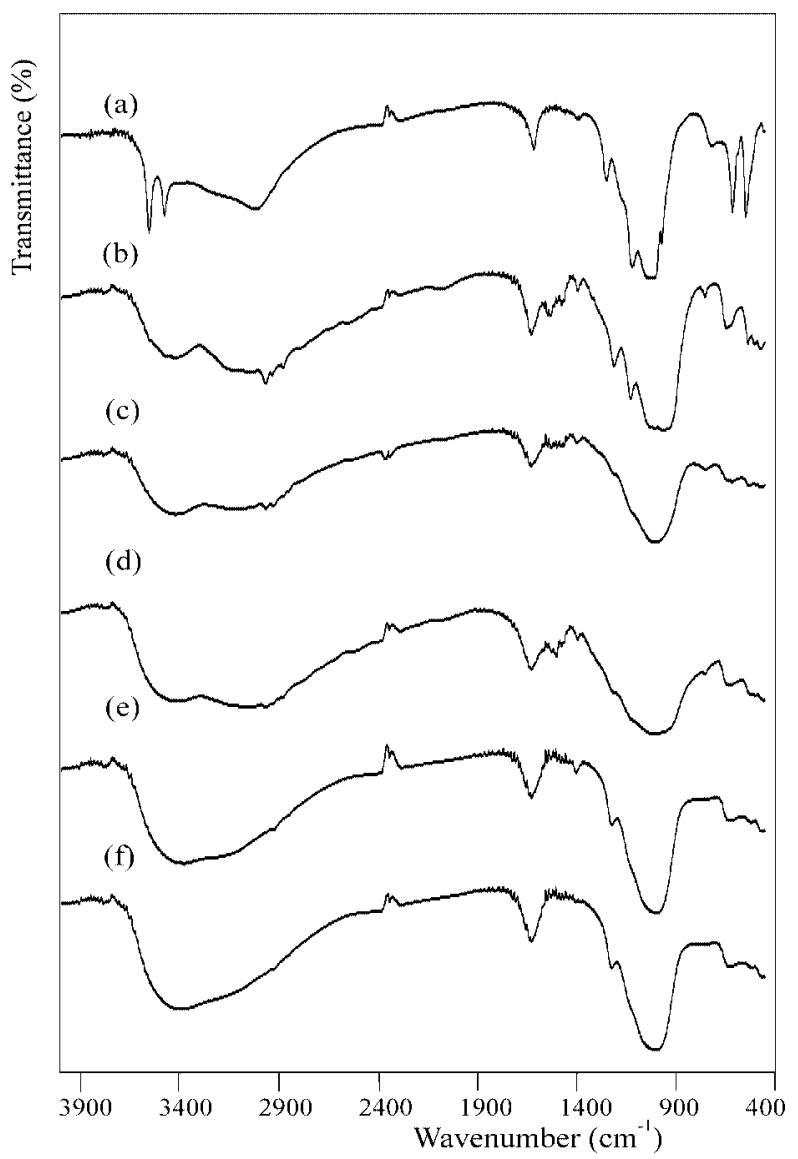

Figure 3 IR espectra: (a) $\alpha$-TiP; (b) $\alpha$-TiP/PrA; and finally, ironmetal phases [(c) $\mathrm{Fe}_{1} \mathrm{TiP}$; (d) $\mathrm{Fe}_{2} \mathrm{TiP}$; (e) $\mathrm{Fe}_{8} \mathrm{TiP}$; (f) $\mathrm{Fe}_{10} \mathrm{TiP}$.

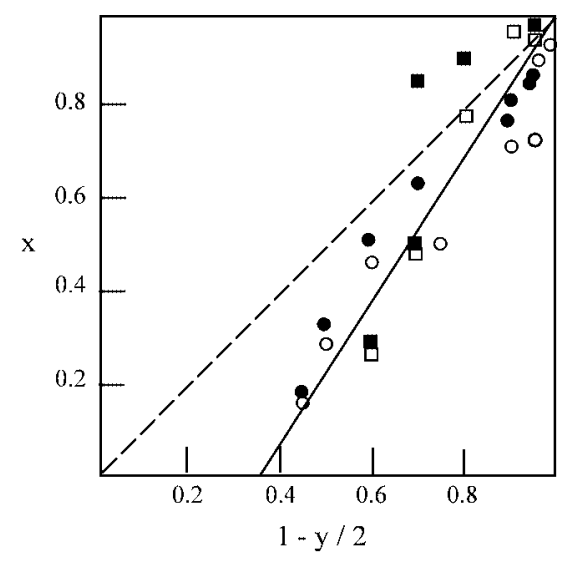

Figure $4 \mathrm{M}_{\mathrm{N}} \mathrm{TiP}$ compounds: amount of $\mathrm{TM}\left(\boldsymbol{\square} \mathrm{Co}^{2+}, \square \mathrm{Ni}^{2+}\right.$, $\bigcirc \mathrm{Fe}^{3+}, \mathrm{Cr}^{3+}$ ) in solid phase as a function of the amount of evacuated propylamine (the dashed line marks the behaviour if the process took place by means of a simple propylamonium/transition-metal-cation ion-exchange mechanism).

transition-metal cations. Independently of this fact, the amount of residual amine is very small in the metal-saturated phases.

The SEM images, which allow us to monitor how the morphology of the sample evolves during the above com- 

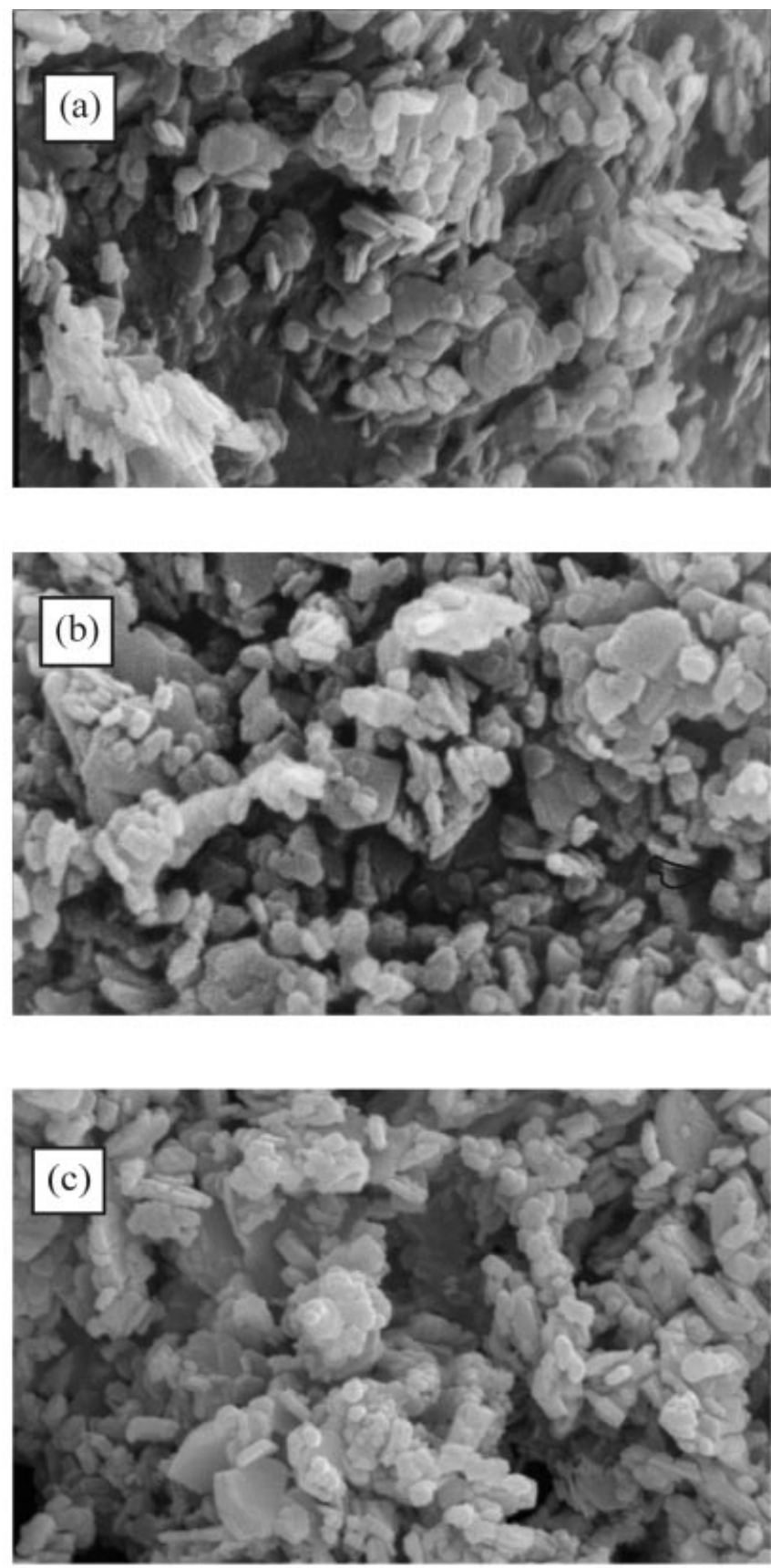

\section{I $\mu \mathrm{m}$}

Figure 5 SEM images: (a) $\alpha$-TiP; (b) $\alpha$-TiP/PrA and (c) $\mathrm{Fe}_{10} \mathrm{TiP}$.

mented process, are show in Figure 5. The combination of XRD and SEM shows that the $\alpha$-TiP is constituted by pseudohexagonal plates of average dimensions $5000 \times 5000$ $x 1850 \AA^{3}$ [20]. The application of these techniques to the both $\alpha-\mathrm{TiP} / \mathrm{PrA}$ and $\mathrm{M}_{\mathrm{N}} \mathrm{TiP}$ compounds indicates that although their morphology is quite similar, measurable differences are observed. In relation to starting material $\alpha$-TiP, the plates width remains quite constant, whereas the average area of the face of the plate decreases slightly.

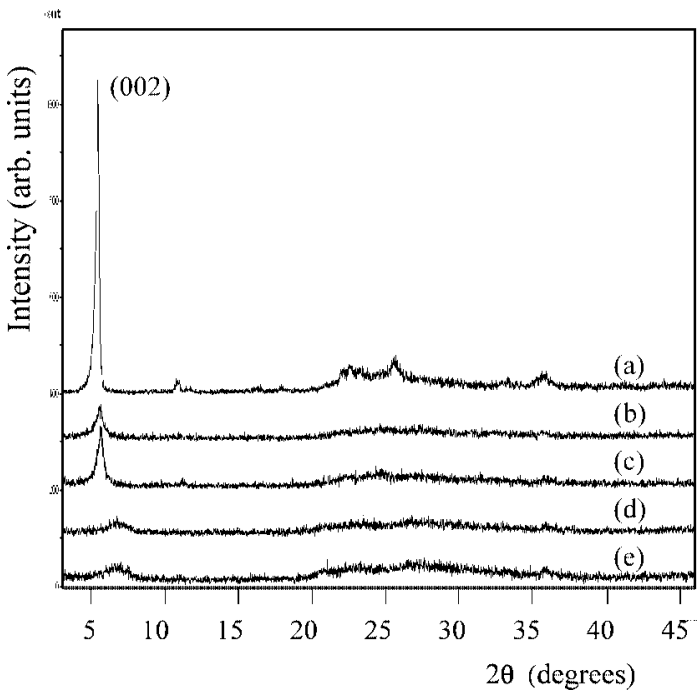

Figure 6. Powder X-ray diffraction patterns: (a) $\alpha$-TiP/PrA; (b) $\mathrm{Fe}_{1} \mathrm{TiP}$; (c) $\mathrm{Fe}_{2} \mathrm{TiP}$; (d) $\mathrm{Fe}_{8} \mathrm{TiP}$; (e) $\mathrm{Fe}_{10} \mathrm{TiP}$.

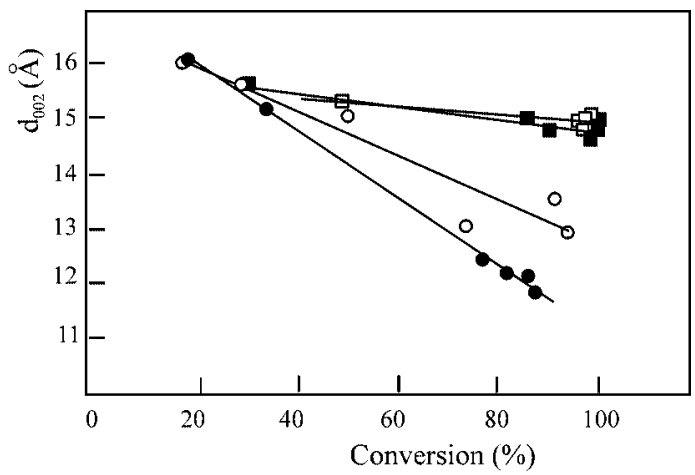

Figure 7 Interlayer planar distance $d_{002}$ of the materials $\mathrm{M}_{\mathrm{N}} \mathrm{TiP}$ as a function of the TM $\left(\square \mathrm{Co}^{2+}, \square \mathrm{Ni}^{2+}, \bigcirc \mathrm{Fe}^{3+}, \mathrm{Cr}^{3+}\right)$ conversion (see Eq. (2) in the text) in the basal spacing. Note that the distance $\mathrm{d}_{002}$ has change after the treatment with propylamine.

The powder X-ray diffraction pattern of the different samples after accomplishing the different steps on the synthesis route are show in Figure 6. It can be seen that the clearest pattern that originated after the intercalation of the $3 \mathrm{~d}$ cations is the loss of long range order in these materials, and the increases of the $\mathrm{d}_{002}$ interplanar distance (see Fig. 7) with the propylamine. After the intercalation process this distance $\mathrm{d}_{002}$ decreases with the TM conversion, becoming amorphous for the higher amount of TM within the interlayer spacing. Moreover, the effect is more accused in the tri-valent ions than in the di-valents ones (Fig. 7).

Figure 8 compiles the thermal analysis data of three representative samples of the $\mathrm{Cr}_{\mathrm{N}}$ TiP family. The thermogravimetric curves shows that the thermal decomposition of new materials takes place in two well-differentiated temperature zones. In the first stage, at temperatures lower than $200^{\circ} \mathrm{C}$, the weakly bonded water is desorbed. The weight loss at higher temperatures is due, sequentially, to the both strongly linked interlayer species (crystallization water and 


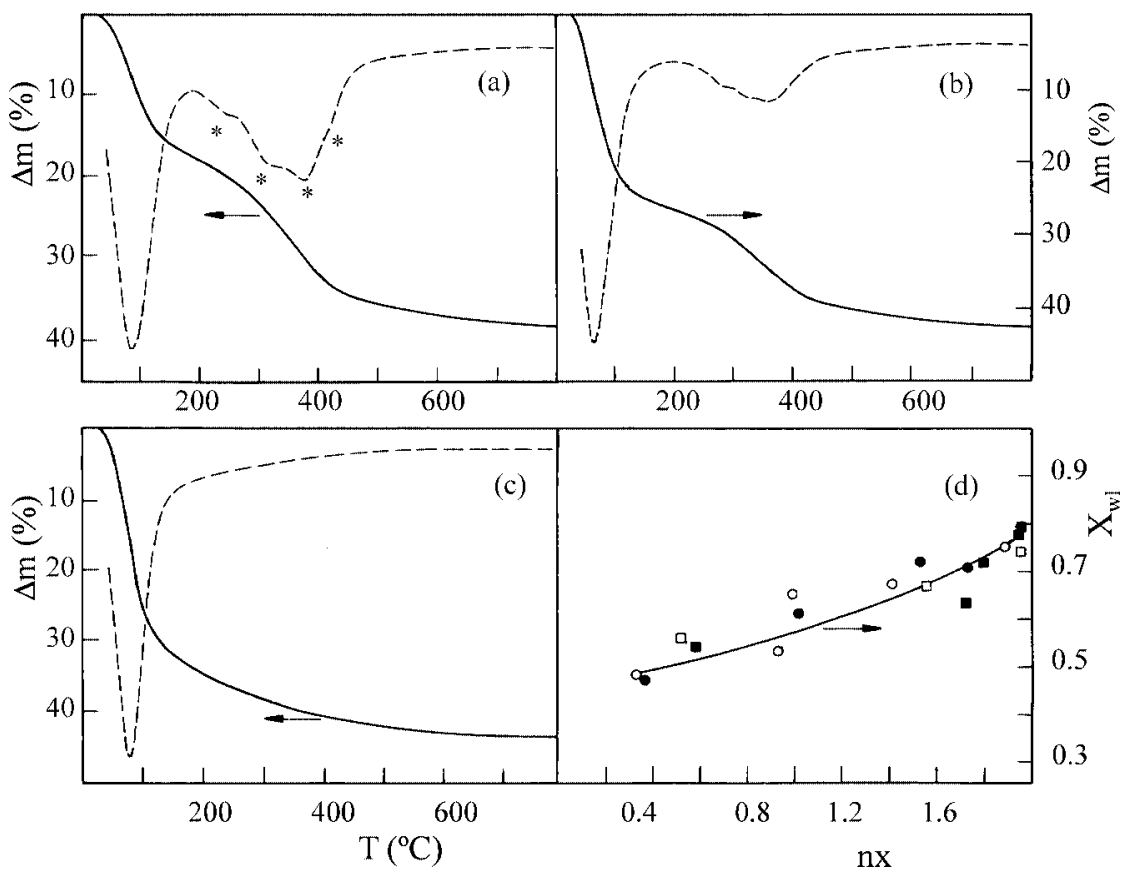

Figure 8 TG (-) and DTG (- - - ) curves: (a) $\mathrm{Cr}_{1} \mathrm{TiP}$; (b) $\mathrm{Cr}_{3} \mathrm{TiP}$; (c) $\mathrm{Cr}_{10} \mathrm{TiP}$. (d) Weight loss fraction $\mathrm{X}_{\mathrm{wl}}$, in $\mathrm{TiM}_{\mathrm{x}} \mathrm{H}_{2-\mathrm{nx}}\left(\mathrm{PO}_{4}\right)_{2} \cdot \mathrm{yC}_{3} \mathrm{H}_{7} \mathrm{NH}_{2} \cdot \mathrm{wH}_{2} \mathrm{O}$ at $200{ }^{\circ} \mathrm{C}$ (with respect to the weight loss at $800{ }^{\circ} \mathrm{C}$ ) as a function of nx value $\left(\square \mathrm{Co}^{2+}, \square \mathrm{Ni}^{2+}\right.$, $\left.\mathrm{Fe}^{3+}, \mathrm{Cr}^{3+}\right)$.

propylamine) and hydrogenphosphate group condensation. These processes are manifested as shoulders in the DTGcurve (see asterisks in the Fig. 8a). When the ion-substitution degree increases, the concentration of both organic and hydroxyl groups decrease in the interlayer space. In Fig. $8 \mathrm{~d}$ it can be observed the relative importance of the weight loss due to these groups with respect to that it takes place at a lower temperature.

Figure 9a contains the normalized Ni-edge EXAFS spectra for the $\mathrm{Ni}_{10} \mathrm{TiP}$ compound as a representative example. It is worth nothing that all the X-ray-absorption spectra are quite similar for the different $3 \mathrm{~d}$ cations, showing an important dependence on the temperature. Thus, the data can be compared in terms of phase and amplitude of the EXAFS oscillations to determine similarities or differences between the samples studied and also to provide information as to the signal-to-noise characteristics of the experiment. The Fourier-transformed EXAFS data for $\mathrm{Ni}_{10} \mathrm{TiP}$ is presented in Fig. 9b. All the data resemble closely one each other, the relative amplitude and radial distance of Fourier peaks appearing over the range 1 to $7 \AA$.

From the intensity of the first peak we conclude that each $\mathrm{Ni}$ atom in this $\mathrm{Ni}_{10} \mathrm{TiP}$ compound is octahedral and is surrounded by 6 oxygen atoms, the Ni-O distance being $2.06 \AA$. This EXAFS X-ray results are consistent with the $\mathrm{X}$-ray diffraction data. The former are completely explained by picturing the $\alpha$-titanium phosphate after the intercalation of the $3 \mathrm{~d}$ cations: each $\mathrm{Ni}$ atom has a definite number of nearest neighbours at a definite distance, but not unit of structure repeats itself identically at regular internals in three dimensions, and the materials are not crystalline after
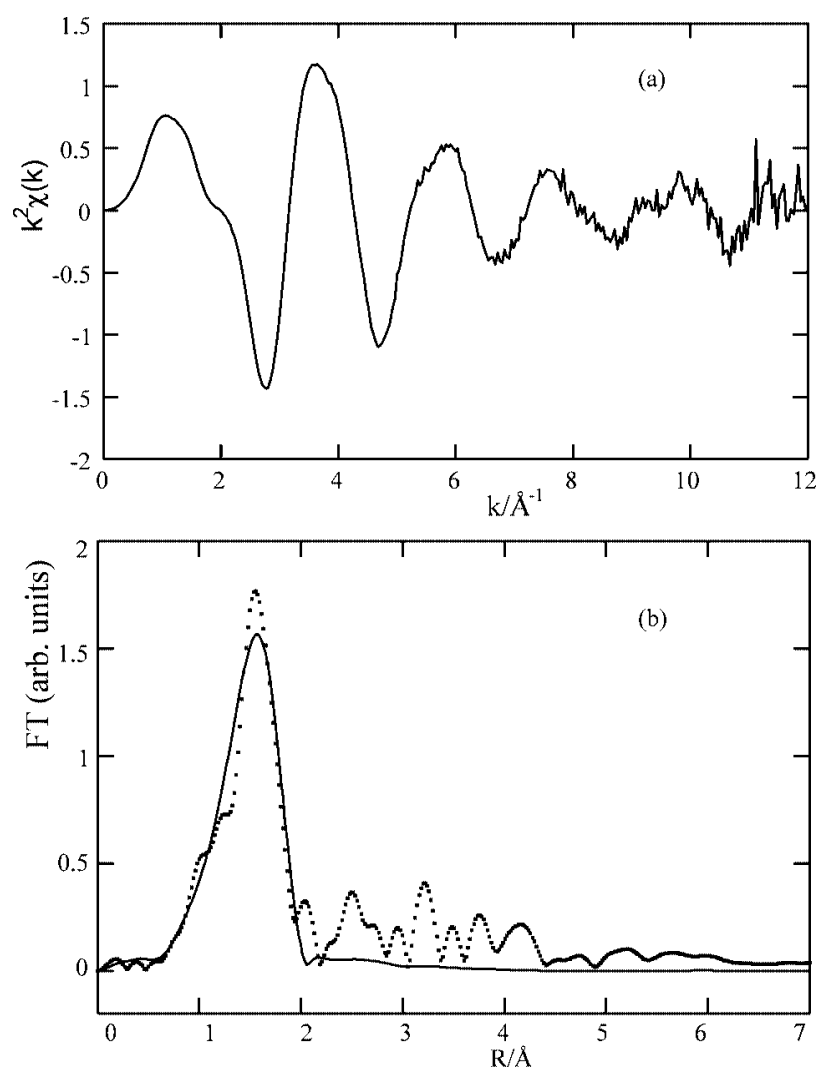

Figure 9 (a) Normalised EXAFS data after background removal and conversion to photoelectron wave-vector for $\mathrm{Ni}_{10} \mathrm{TiP}$. (b) Fourier-transformed $\mathrm{Ni}_{10}$ TiP EXAFS data. All the data were treated using single scattering amplitudes and phases taken from McKale. 


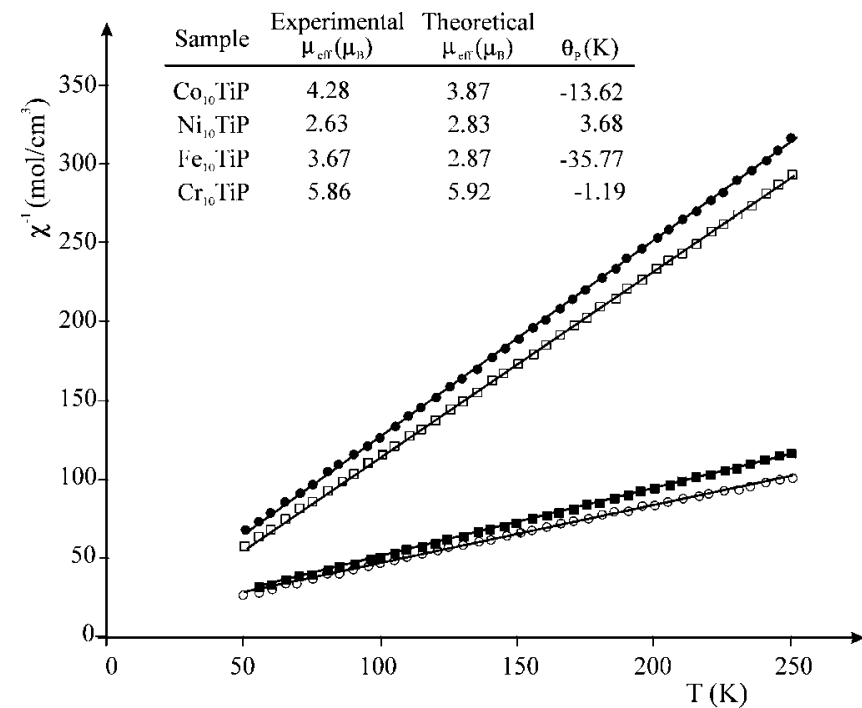

Figure 10 Temperature dependence of the reciprocal magnetic susceptibility for the $\mathrm{M}_{10} \mathrm{TiP}\left(\square \mathrm{Co}^{2+}, \square \mathrm{Ni}^{2+}, \bigcirc \mathrm{Fe}^{3+}, \mathrm{Cr}^{3+}\right)$. The upper part contains information on the experimental and theoretical paramagnetic moments $\mu_{\mathrm{eff}}$ and the paramagnetic Curie temperature $\theta_{\mathrm{P}}$ (see text).

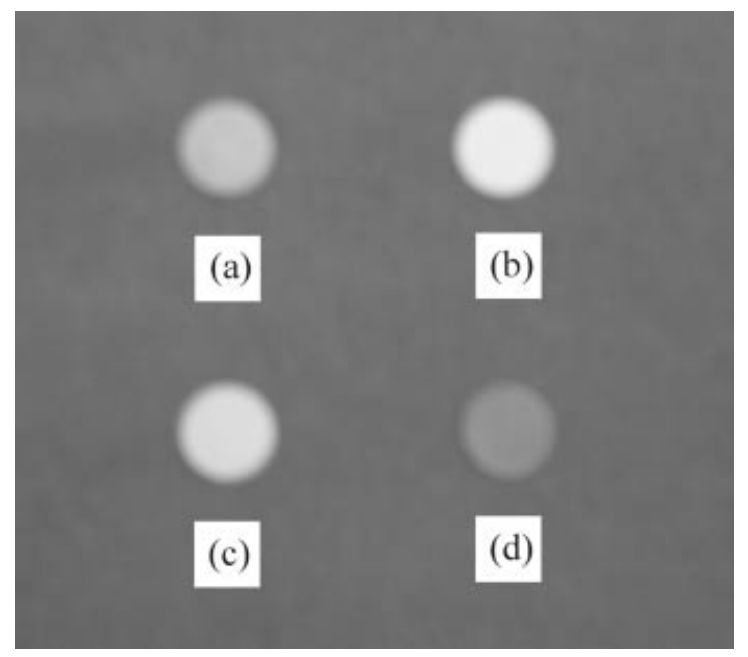

Figure 11 Photography of the samples: (a) $\mathrm{Co}_{10} \mathrm{TiP}$; (b) $\mathrm{Ni}_{10} \mathrm{TiP}$; (c) $\mathrm{Fe}_{10} \mathrm{TiP}$ and (d) $\mathrm{Cr}_{10} \mathrm{TiP}$.

the intercalation process. For the analysis only first nearestneighbours have been taken into account. Although we have made several differents attempts for describing the rest of Fourier peaks no satisfactory models were found considering second and/or third nearest neighbors. Further experiments using small angle X-ray or neutron scattering could help us in explaining more in detail the microstructure of these materials.

The X-ray absorptions, XANES and EXAFS, corresponding to lines $\mathrm{K}$ of respective ions $\left(\mathrm{Co}^{2+}, \mathrm{Ni}^{2+}, \mathrm{Fe}^{3+}\right.$, $\mathrm{Cr}^{3+}$ ) were measured at room temperature with the purpose to study the local order around the metal transition ions for some selected samples (fraction of the interleave: 0.1,
$0.2,0.3,1.0)$, as well as the evolution in temperature (150, 450 and $600^{\circ} \mathrm{C}$ ) for compositions 0.1 and 1.0. The local environments have been revealed independent of the composition of the material but it varies markedly with the heat treatment.

The measurements of the magnetic susceptibility, $\chi$, as a function of the temperature were performed in the intercalated phases of the $\alpha-T i P / \operatorname{PrA}$ samples with the richest $\mathrm{Co}^{2+}$, $\mathrm{Ni}^{2+}, \mathrm{Fe}^{3+}$ and $\mathrm{Cr}^{3+}$ ion concentrations. For these compositions no magnetic order was detected in the range of temperatures measured from $300 \mathrm{~K}$ to $1.8 \mathrm{~K}$. In all the cases, the magnetic susceptibility is characterized for exhibiting a $\mathrm{Cu}-$ rie-Weiss law, see Eq. (3), where $\mathrm{C}$ is the Curie constant for the $3 \mathrm{~d}$ ions and $\theta_{\mathrm{p}}$ is the paramagnetic Curie temperature. The theoretical value can be obtained applying Eq. (4).

$$
\chi=\frac{C}{T-\theta_{p}}
$$

$\mathrm{C}=\mathrm{N}_{\mathrm{A}} \frac{[\mathrm{L}(\mathrm{L}+1)+4 \mathrm{~S}(\mathrm{~S}+1)]}{3 \mathrm{k}_{\mathrm{B}}} \mu_{\mathrm{B}}^{2}$

From the analysis of the mentioned laws we have been able to extract the information on the total spin angular momentum and the paramagnetic Curie temperature (see table in Fig. 10). The former is in quite good agreement with that obtained from the Hund's rules assuming that the total orbital angular momentum is zero. This phenomenon is known as the quenching of the total angular momentum, owing to the existence of a crystalline electric field (CEF) created by the local environment around the $3 \mathrm{~d}$ cations. This CEF is also responsible for the different colours that present the $\mathrm{M}_{\mathrm{N}} \mathrm{TiP}$ materials studied, (see the photo in Fig. 11). Up to now we have been able to synthesize only polycrystalline samples of these materials. This feature limits further more precise optical measurements for determining the CEF state and splitting of the $3 \mathrm{~d}$ ions in the octahedral symmetry that we have deduced from our EXAFS data.

In conclusion, we have shown that our experimental procedure enabled the preparation of new $\alpha$-titanium phosphate/propylamine intercalation compounds containing metal ions such $\mathrm{Co}^{2+}, \mathrm{Ni}^{2+}, \mathrm{Fe}^{3+}$ or $\mathrm{Cr}^{3+}$ that exhibit optical properties, although these materials do not present a long range crystalline order. Further efforts are needed for crystallising new materials where both optical and magnetic properties could be combined.

Acknowledgment. This work was supported by MEC (Spain), Research Projects Nos. MAT2002-04178-C04 and MAT2003-02940. We thank both Dr. Stuart Ansell (ESRF) for his help during the EXAFS experiments and the ESRF for the provision of the synchrotron beam time.

\section{References}

[1] J. S. Miller, Adv. Mater. 1990, 2, 98.

[2] O. Kahn, Adv. Inorg. Chem. 1995, 43, 179. 
[3] A. Goñi, J. Rius, M. Insausti, L. Lezama, J. L. Pizarro, M. I. Arriortua, T. Rojo, Chem. Mater. 1996, 8, 1052. M. RiouCavellec, J. M. Grenèche, D. Riou, G. Férey, Chem. Mater. 1998, 10, 2434. S. Hwu, Chem. Mater. 1998, 10, 2846. J. Escobar, J. L. Mesa, J. L. Pizarro, L. Lezama, R. Olezcuaga, T. Rojo, J. Mater. Chem. 1999, 9, 2691. J. M. Rojo, J. L. Mesa, L. Lezama, J. L. Pizarro, M. I. Arriortua, J. Rodríguez Fernández, G. E. Barberis, T. Rojo, Phys. Rev. 2002, B66, 0944006. C. V. Krishnamohan, C. C. Chusuei, R. Clérac, T. Möller, K. R. Dunbar, A. Clearfield, Inorg. Chem. 2003, 42, 8300.

[4] A. Peña, J. Gutiérrez, J. M. Barandiarán, J. L. Pizarro, T. Rojo, L. Lezama, M. Insauati, M. M. M. 2001, 226-230, 831. H. Kageyama, L. Viciu, G. Caruntu, Y. Ueda, J. B. Wiley, J. Phys.: Condens. Matter 2004, 16, S585.

[5] B. G. Shpeizer, D. M. Poojary, K. Ahn, C. E. Runyan, A. Clearfield, Science 1994, 266, 1357. B. G. Shpeizer, P. Sylvester, R. A. Cahill, A. Clearfield, Chem. Mater. 1999, 11, 1201. E. Coronado, J. R. Galán-Mascarós, C. J. Gómez García, V. Laukhin, Nature. 2000, 208, 447.

[6] A. Goñi, L. Lezama, J. L. Pizarro, J. Escobar, M. I. Arriortua, T. Rojo, Chem. Mater. 1999, 11, 1752.

[7] A. Clearfield, J. A. Stynes, J. Inorg. Nucl. Chem. 1964, 26, 117.

[8] J. M. Troup, A. Clearfield, Inorg. Chem. 1977, 16, 3311.
[9] A. M. K. Andersen, P. Norby, J. C. Hanson, T. Voyt, Inorg. Chem. 1998, 37, 876.

[10] G. Alberti, E. Torracca, J. Inorg. Nucl. Chem. 1968, 30, 317.

[11] C. Trobajo, S. A. Khainakov, A. Espina, J. R. García, Chem. Mater. 2000, 12, 1787.

[12] S. Bruque, M. A. G. Aranda, E. R. Losilla, P. Olivera-Pastor, P. Maireles-Torres, Inorg. Chem. 1995, 34, 893.

[13] A. Espina, E. Jaimez, S. A. Khainakov, C. Trobajo, J. R. García, J. Rodríguez, Chem. Mater. 1998, 10, 2490.

[14] C. Trobajo, M. Suárez, J. Rodríguez, J. Radioanal. Nucl. Chem. 1991, 149, 67.

[15] G. Alberti, P. Cardini-Galli, U. Constantino, E. Torraca, J. Inorg. Nucl. Chem. 1967, 27, 571.

[16] M. B. Dines, R. E. Cooksey, P. C. Griffith, R. H. Lane, Inorg. Chem. 1983, 22, 1003.

[17] F. Menéndez, A. Espina, C. Trobajo, J. Rodríguez, Mater. Res. Bull. 1990, 25, 1531.

[18] W. J. Williams, in Handbook of Anion Determination, Butterworths, London 1984.

[19] K. V. Klementev, Package "VIPER (visual processing in EXAFS researches) for windows", Nucl. Inst. Meth. Phys. Res. 2000, A448, 299.

[20] A. Espina, E. Jaimez, J. H. Guil, J. B. Parra, J. R. García, J. Rodríguez, J. Phys. Chem. 1998, 102, 1913. 